\title{
Estimation efficiency of rewound induction motors in situ using a numerical model
}

\author{
Mohamed Kaddari' ${ }^{1}$, Mahmoud El Mouden ${ }^{2}$, Abdelowahed Hajjaji ${ }^{3}$, Semlali Abdellah ${ }^{4}$ \\ ${ }_{1,2,3}$ Laboratory of Engineering Sciences for Energy (LabSIPE), National School of Applied Sciences, Morocco \\ ${ }^{4}$ Laboratory of Condensed Matter Physics (LPMC), Faculty of Sciences, Chouaib Doukkali University, Morocco
}

\begin{abstract}
Article Info
Article history:

Received Feb 2, 2020

Revised Apr 19, 2020

Accepted May 10, 2020

Keywords:

Efficiency estimation

Energy savings

Industry

Numerical model

Rewound induction motor

ABSTRACT

This paper presents an effective technique for determining the impact of rewinding practices on the motor efficiency and characterizing the efficiency reduction when electrical motors are rewound several times. This technique focuses on a new approach and a statistical study to find a numerical model for the estimation efficiency of rewound induction motors in the field. The experimental results from 101 induction motor tests are analyzed. A numerical model is determined and compared with different methods: separate losses method, modified current method and simple current method. An error analysis is conducted to examine the level of uncertainty by testing three asynchronous motors at $110 \mathrm{~kW}, 160 \mathrm{~kW}$, and $300 \mathrm{~kW}$. The results show that this approach can predict and estimate the efficiency reduction in rewound motors without expensive tests and can help the energy manager make effective cost decisions in replacing the rewound motors with more efficient ones by using an assessment of overconsumption and maintenance costs. Another advantage of this model is that it can be used to improve the software tools and can also be a very strong indicator to audit the repair quality.
\end{abstract}

This is an open access article under the CC BY-SA license.

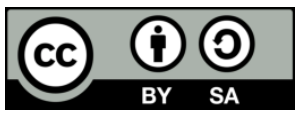

\section{Corresponding Author:}

Mohamed Kaddari,

Laboratory of Engineering Sciences for Energy,

Chouaib Doukkali University,

Fax: +212 5233949 15, National School of Applied Sciences, El Jadida, Morocco.

Email: moh.kaddari@gmail.com

\section{INTRODUCTION}

Increased energy demand, fluctuations in oil prices, energy supply uncertainties and concerns regarding global warming have reinforced the priority given by several countries around the world to energy efficiency policies. Electrical motors and more specifically, induction motors are the main loads in electrical power systems of industrialized countries [1]. The enormous number of these machines represents a significant potential for the application of demand side energy management techniques $[2,3]$. The efficient operation of the motors can bring direct and important savings in consumed energy levels and indirectly reduce greenhouse gas emissions. Improving energy efficiency in industry involves first an accurate assessment of electricity consumption, and therefore an accurate assessment of the efficiency of electric motors, as they are the most energy-intensive equipment in industry.

Generally, the measurement of efficiency is based on the measurement of the input power $\left(\mathrm{P}_{\text {in }}\right)$ and the output power $\left(\mathrm{P}_{\text {out }}\right)$. These types of methods require decoupling and moving the motor from the industrial process to the laboratory. However, the evaluation can also be performed indirectly by evaluating the various losses of the motor by using a minimum of measurements accessible on-site or by 
estimating the machine parameters $[4,5]$. On-site measurements make it possible to minimize the evaluation efficiency period since no movement of the motor to the laboratories is necessary $[6,7]$.

Several papers have also been published regarding efficiency evaluations of induction motors on-site. However, very little has been done on estimating the efficiency after a rewinding process, which in fact can affect many induction motors in the industrial sector. The real efficiency of a motor is usually different from the value mentioned on its nameplate, because the efficiency may decrease significantly due to ageing or rewinding [8], which creates an overconsumption of electrical energy. In this paper, a new approach referred to as the local statistical method (LSM) is proposed for this purpose, which requires only the results of in-situ no-load testing during the rebuilding phase and one measurement point on load. The proposed technique is validated by field and experimental results with three induction motors.

\section{FORMULATION OF THE PROBLEM}

In industry, park machines are generally equipped with thousands of motors that have been rewound several time, and traditional methods of rewinding and refurbishment can decrease the efficiency. When the refurbishment does not respect the requirements of Electrical Apparatus Service Association (EASA) standard, the motors can easily lose $10 \%$ of the initial value shown on the nameplate [9]. Generally, electrical machine rebuilding and refurbishment centers do not have the funds to test their machines with the well-accepted efficiency test of the IEEE standard 112 or the new IEC Standard 60034-2-1 [10]. In fact, these facilities can only start up the motors and run them under a no-load condition with their autotransformers. Thus, they generally do not present any information regarding the efficiency degradation of an induction motors after its repair [11].

The authors in [12] proposed measures to improve the energy efficiency and the availability of electric motors in industry because to have high-efficiency motors in factories is just a step but not an end in itself, and the efficiency of motors is decreased when the motor is rewound. Therefore, for an electric motor to remain efficient in time with lasting durability, proper maintenance and protection is necessary. There are several computer tools and software packages to calculate the gain of replacing old motors with a new high-efficiency motor [13]. However, these tools cannot provide information regarding the reduction in efficiency after the refurbishment of a machine. Refurbishment workshops with best practices on rewinding procedures can often repair and rewind motors with no important efficiency reduction; hence, there is a need to develop an indicator of the repair quality.

The rest of this manuscript is organized as follows: in section 3, the proposed methodology is presented in detail. The experimental results and analysis are detailed in section 4 . Section 5 presents the numerical model and the developed algorithm. In section 6 describe a validation of the proposed numerical model by comparison to real measurements. Section 7 offers a discussion and then the conclusions are presented in section 8 .

\section{METHODOLOGY}

Over the years, the problem of efficiency reduction $(\Delta \eta)$ has been observed by an increase in electrical consumption of rewound motors. Subramanian and Bhuvaneswari [14] presented a new method for the determination of induction motor efficiency using an evolutionary programming technique. This method is very accurate and does not require no-load measurements. However, when an electric motor is damaged it will automatically rewind, and in this evident situation lays the importance of this technique. Therefore, in this paper we will use the results of no-load tests that we normally and easily perform after each rewinding operation, adding a one-measurement point on load in situ. The idea of the method is to characterize the reduction in efficiency according to the number of rewinds and the rated power. The available data for this method are as follows: one point on load condition from the site, the current under no-load test conditions, the line voltage, the value of the stator resistance and the nameplate data.

The estimation of the efficiency can be based on one or more methods combined. These methods differ in their precision, implementation and convenience compared to the operating conditions [15-18]. In our case, decoupling the motor from its load will not be required, and the exploitation of the obtained results during the repair of hundreds of motors will enable us to evaluate the efficiency reduction based on the rated power $\left(P_{u}\right)$ and the number of rewinding $\left(N_{R}\right)$. Our searched system is as follows $\Delta \eta=f\left(N_{R}, P_{u}\right)$.

For this analysis, we will consider hundreds of electric motors from a workshop for rebuilding and refurbishment. Then, the results are listed in a table, in which the stray load losses $\left(\mathrm{P}_{\text {sll }}\right)$, stator copper losses, windage and friction losses were calculated. The rotor copper losses were ignored. A statistical study to predict the efficiency reduction was conducted. Then, multiple linear regressions were utilized to solve the equations by using MATLAB software. 


\subsection{Definition of motor losses and efficiency}

The analysis of the motors by measuring the losses is particularly useful to understand how the conditions in which repairs are carried out affect the efficiency. For the purposes of an efficiency evaluation, motor losses are classified into five categories: stator copper losses $\left(\mathrm{P}_{\mathrm{sc}}\right)$, rotor copper losses $\left(\mathrm{P}_{\mathrm{rc}}\right)$, stray load losses $\left(\mathrm{P}_{\mathrm{sll}}\right)$ [19], windage and friction losses $\left(\mathrm{P}_{\mathrm{wf}}\right)$ and core losses $\left(\mathrm{P}_{\mathrm{cl}}\right)$. The first three losses vary according to the load, while the other two losses are independent of the load. Even though, the windage and friction loss are almost constant, we are talking about an asynchronous motor and speed varies about 3\% from no-load to rated load. The windage varies with the speed raised to the third power. Therefore, the windage and friction loss varies with the load.

The electric motor absorbs a power $\left(\mathrm{P}_{\mathrm{in}}\right)$ from the electrical network and transmits only a transmitted power $\left(\mathrm{P}_{\text {tr }}\right)$ to the rotor after dissipating part of the power in the form of copper losses $\left(\mathrm{P}_{\mathrm{sc}}\right)$ and iron losses $\left(\mathrm{P}_{\text {is }}\right)$ at the stator. There are also copper losses $\left(\mathrm{P}_{\mathrm{rc}}\right)$, iron losses $\left(\mathrm{P}_{\mathrm{ir}}\right)$ at the rotor, mechanical losses at the bearings and the stray load losses. Koprivica in [19] presents an application of one simple and accurate method for the measurement of stray load losses (additional load losses) in induction machines. The accurate prediction of losses [20] and speed [21, 22] of induction machines is an up-to-date topic of high interest in both industrial environments and the academic and research world.

\subsection{Induction motor power flow}

Stator copper losses $\left(\mathrm{P}_{\mathrm{sc}}\right)$ are losses in the stator windings. Rotor copper losses $\left(\mathrm{P}_{\mathrm{rc}}\right)$ are the losses in the rotor windings including the brush contact losses for wound-rotor motors. These losses are determined from the per-unit slip using (1), [15].

$$
\mathrm{P}_{\mathrm{rc}}=\left(\mathrm{P}_{\mathrm{in}}-\mathrm{P}_{\mathrm{sc}}-\mathrm{P}_{\mathrm{cl}}\right) \times \mathrm{S}
$$

where $\mathrm{S}$ is the slip and $\mathrm{P}_{\mathrm{cl}}$ (core loss) is a result of an alternating magnetic field in a core material.

A no-load test supplies the motor without a load and measures the power absorbed (Pin0). This test will determine the collective losses (Pc), which remain constant regardless of the load. The absorbed power in the general case is:

$$
P_{\text {in }}=\sqrt{3} . \text { U. I. } \cos \phi
$$

where $\mathrm{P}_{\text {in }}$ is the input power of the motor. The index ' 0 ' will be added to denote the formulas of the no-load test, such as in (2) below for the stator copper losses under no-load test conditions.

$$
\mathrm{P}_{\mathrm{sc} 0}=\frac{3}{2} \cdot \mathrm{R}_{\mathrm{s}} \cdot \mathrm{I}_{0}^{2}
$$

The core losses $\left(\mathrm{P}_{\mathrm{cl}}\right)$ are due to the magnetizing hysteresis and eddy currents in the iron [23]. This parameter varies approximately with the square of the input voltage. However, for a fixed voltage, it remains approximately constant from the no-load case to the full-load case. The core loss is usually measured from the no-load test. Friction and windage losses $\left(\mathrm{P}_{\mathrm{wf}}\right)$ are the mechanical rotational losses due to the friction and windage. This value is also practically constant from the no-load case to the full-load case and is generally measured from the no-load test [15].

$$
\begin{aligned}
& P_{c}=\left(P_{c l}+P_{w f}\right) \\
& P_{c}=\sqrt{3} \cdot U_{0} \cdot I_{0} \cdot \cos \phi_{0}-\frac{3}{2} \cdot R_{s} \cdot I_{0}^{2}
\end{aligned}
$$

The power flow is:

$$
\mathrm{P}_{\mathrm{in}}=\mathrm{P}_{\text {out }}+\mathrm{P}_{\mathrm{sc}}+\mathrm{P}_{\mathrm{rc}}+\mathrm{P}_{\mathrm{c}}+\mathrm{P}_{\mathrm{sll}}
$$

where $\mathrm{P}_{\text {out }}$ is the output power of the motor. Therefore, the power flow under no-load test conditions is given by:

$$
\mathrm{P}_{\mathrm{c}}=\mathrm{P}_{\mathrm{in} 0}-\mathrm{P}_{\mathrm{sc} 0}
$$

Below are the formulas for calculating the efficiency reduction of the rewound motor. The losses due to the load are:

$$
P_{\text {losses }}=\left(\sqrt{3} \cdot U_{0} \cdot I_{0} \cdot \cos \phi_{0}-\frac{3}{2} \cdot R_{\mathrm{S}} \cdot I_{0}^{2}\right)+\frac{3}{2} \cdot R_{\mathrm{s}} \cdot \mathrm{I}^{2}+\mathrm{P}_{\text {sll }}
$$


The actual efficiency $\left(\eta_{\mathrm{a}}\right)$ of motor is then defined as:

$$
\eta_{\mathrm{a}}=\frac{\mathrm{P}_{\text {in }}-\mathrm{P}_{\text {losses }}}{\mathrm{P}_{\text {in }}}
$$

The efficiency reduction $\Delta \eta$ is:

$$
\Delta \eta=\eta_{\mathrm{n}}-\eta_{\mathrm{a}}
$$

where $\eta_{\mathrm{n}}$ is the efficiency mentioned in the nameplate.

\subsection{Regression linear multiple analysis}

Multiple linear regressions are the most common figures in a linear regression analysis. As a predictive analysis, multiple linear regressions are used to explicate the relationship between the dependent variable from two or more independent variables. Our system is composed of three characters:

- $\mathrm{P}_{\mathrm{u}}=\mathrm{X}^{1}$ : The rated power of the rewound motor

- $\mathrm{N}_{R}=\mathrm{X}^{2}$ : Number of rewinding operations

- $\Delta \eta=Y$ : Reduction in the efficiency after each rewinding

For reasons of simplicity, the chosen model is a linear regression; thus, the numerical model takes the following form:

$$
Y=\alpha_{0}+\alpha_{1} \cdot \alpha X^{1}+\alpha_{2} \cdot X^{2}
$$

These equations are stacked together and written in vector form as follows:

$$
\begin{aligned}
& Y=\left[\begin{array}{c}
y_{1} \\
\ldots \\
y_{n}
\end{array}\right] ; \alpha=\left[\begin{array}{c}
\alpha_{1} \\
\ldots \\
\alpha_{n}
\end{array}\right] ; e=\left[\begin{array}{c}
e_{1} \\
\ldots \\
e_{n}
\end{array}\right] \\
& Y=\left[\begin{array}{c}
\Delta y_{1} \\
\ldots \\
\Delta y_{n}
\end{array}\right]=X\left[\begin{array}{ccc}
1 & P_{u 1} & N_{R 1} \\
\ldots & \ldots & \ldots \\
1 & P_{u n} & N_{R n}
\end{array}\right] \cdot \alpha\left[\begin{array}{c}
\alpha_{1} \\
\ldots \\
\alpha_{n}
\end{array}\right]+e\left[\begin{array}{c}
e_{1} \\
\ldots \\
e_{n}
\end{array}\right]
\end{aligned}
$$

We must determine $\alpha_{1}, \alpha_{2}$ and $\alpha_{3}$ such that $\sum_{i}^{n} e_{i}^{2}$ is minimized i.e., $\|e\|^{2}$ is minimized (least square criterion); therefore, we will project orthogonally $\mathrm{Y}$ in $\mathrm{X}^{\mathrm{T}} . \alpha$. The ordinary least squares (OLS) method is the simplest and thus the most familiar estimator. The resolution of the system by MATLAB software is given by (14):

$$
\alpha=\left(X^{\mathrm{T}} \cdot \mathrm{X}\right)^{-1} \cdot \mathrm{X}^{\mathrm{T}} \cdot \mathrm{Y}
$$

To check if the numerical model chosen is good or not, the ratio of the standard deviation of the error to the norm must be calculated. Therefore, if the error is less than $3 \%$, then the chosen model is considered to be good. After finding such a model, if additional values of $\mathrm{N}_{\mathrm{R}}$ and $\mathrm{Pu}$ are given without the associated value of $\Delta \eta$, then the fitted model can be used to create a prediction of the value of the reduction efficiency $\Delta \eta$.

\section{EXPERIMENTAL TEST FOR THE CHARACTERIZATION OF THE EFFICIENCY REDUCTION}

\subsection{Efficiency reduction as a function of the number of rewindings}

Table 1 show the characteristics of an induction motor, which the variation of the efficiency illustrated in Figure 1. After evaluating the losses of this motor, which is rewound 6 times, there is an excess reduction in efficiency that is related to the number of rewinds, the lower load and the oversizing.

Table 1. Specifications of the rewound motor

\begin{tabular}{cccccccc}
\hline $\begin{array}{c}\text { Rated } \\
\text { voltage }(\mathrm{V})\end{array}$ & $\begin{array}{c}\text { Rated } \\
\text { current }(\mathrm{A})\end{array}$ & $\begin{array}{c}\text { Power } \\
\text { factor }\end{array}$ & $\begin{array}{c}\text { Input power } \\
(\mathrm{kW})\end{array}$ & $\begin{array}{c}\text { Nominal } \\
\text { efficiency }(\mathrm{A})\end{array}$ & $\begin{array}{c}\text { Current at no- } \\
\text { load test }(\mathrm{A})\end{array}$ & $\begin{array}{c}\text { Power factor at } \\
\text { no-load test }\end{array}$ & $\begin{array}{c}\text { Resistance of } \\
\text { stator }(\Omega)\end{array}$ \\
\hline 660 & 445 & 0.89 & 452.74 & 0.91 & 100 & 0.17 & 0.5 \\
\hline
\end{tabular}




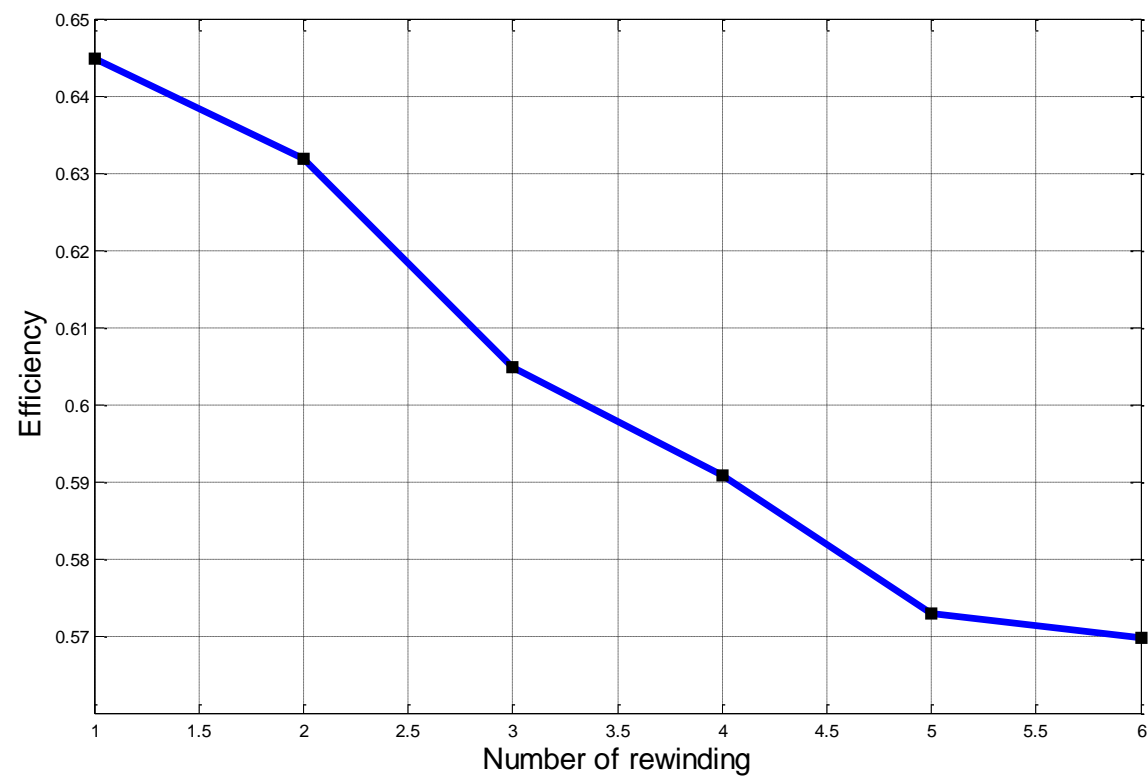

Figure 1. Efficiency dependence on the number of rewinds

\subsection{Efficiency reduction as a function of the rated power}

The second step of the efficiency estimation as a function of the rated power after rewinding consists of selecting motors with different powers, rewinding all the motors at one time and plotting the evolution of the efficiency as a function of the power. From Figure 2, we observe that the performance drop is approximately linear. While the power $\left(\mathrm{P}_{\mathrm{u}}\right)$ increases, the efficiency reduction becomes important.

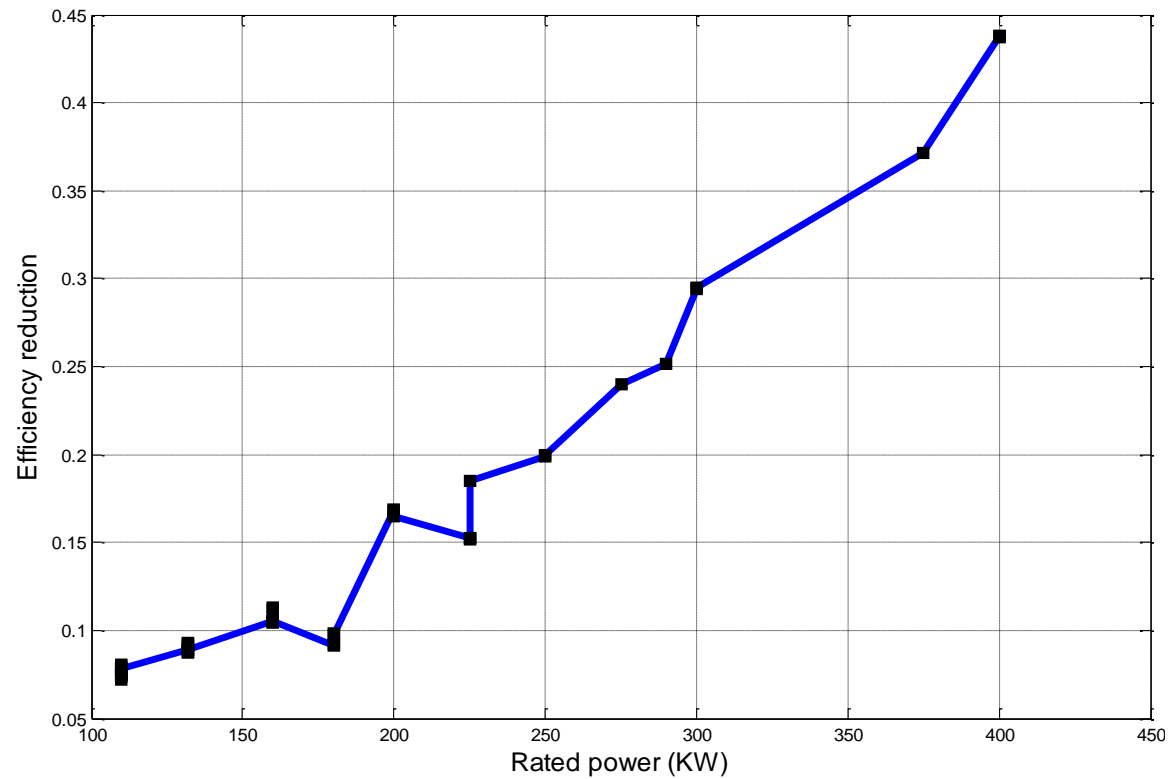

Figure 2. Decrease in the efficiency dependence on the power

\section{EFFICIENCY ESTIMATION OF THE REWOUND MOTORS}

To determine the evolution in the efficiency as a function of the number of rewinds $\left(\mathrm{N}_{R}\right)$ and the rated power $\left(\mathrm{P}_{\mathrm{u}}\right)$ by a multiple linear regression analysis, the motors whose different data and characteristics are known are used. Table 2 shows an extract of the necessary data. 


\begin{tabular}{ccccccccc}
\multicolumn{8}{c}{ Table 2. Sample of available data } \\
\hline No. & $\mathrm{P}_{\mathrm{u}}$ & $\mathrm{N}_{\mathrm{R}}$ & $\mathrm{I}_{\mathrm{n}}$ & $\mathrm{I}_{\text {rew1 }}$ & $\mathrm{I}_{\text {rew } 2}$ & $\mathrm{I}_{\text {rew3 }}$ & $\cos \Phi_{0}$ & $\mathrm{R}_{\mathrm{s}}\left(25^{\circ} \mathrm{C}\right)$ \\
\hline 1 & 375 & 4 & 386 & 90 & 94 & 96 & 0.17 & 0.7 \\
2 & 290 & 3 & 305 & 61 & 65 & 66 & 0.17 & 0.6 \\
5 & 110 & 3 & 118 & 36 & 42 & 46 & 0.17 & 0.5 \\
6 & 132 & 2 & 140 & 46 & 52 & & 0.17 & 0.5 \\
\hline
\end{tabular}

$\mathrm{I}_{\text {rewi }}$ is the current under no-load test conditions for the rewinding operation number $\mathrm{i}$. The selected sample comprises 101 motors of different powers. This sample may have power redundancies provided that the number of rewindings of the motor is different. What interests us the most in this study is the reduction in the efficiency after each rewinding operation.

\subsection{Calculation of the motor efficiency reduction}

It was possible to plot the evolution of the efficiency based on the number of rewinds on the one hand and on the rated power on the other hand. Only the no-load tests were carried out on all the rewound motors by measuring the no-load current $\mathrm{I}_{0}$ and the stator resistance $\mathrm{R}_{\mathrm{s}}$. These measurements were used to calculate the constant losses (mechanical, iron). It is possible to measure another operating point on load in situ. Table 3 contains all the parameters necessary to calculate the reduction in efficiency.

Table 3. Sample of the actual efficiency calculation

\begin{tabular}{ccccccc}
\hline $\mathrm{P}_{\mathrm{u}}(\mathrm{kW})$ & $\mathrm{N}_{\mathrm{R}}$ & $\mathrm{P}_{\text {in }}(\mathrm{kW})$ & $\mathrm{P}_{\mathrm{c}}(\mathrm{kW})$ & $\mathrm{P}_{\mathrm{sc}}(\mathrm{kW})$ & $\mathrm{P}_{\mathrm{SII}}(\mathrm{kW})$ & Efficiency $\left(\mathrm{n}_{\mathrm{a}}\right)$ \\
\hline 160 & 2 & 165.98 & 8.530 & 20.418 & 2.4 & 0.826 \\
290 & 1 & 306.82 & 9.836 & 83.722 & 4.35 & 0.695 \\
375 & 4 & 392.71 & 8.989 & 156.44 & 5.62 & 0.579 \\
\hline
\end{tabular}

\subsection{Determination of the numerical model}

For the resolution of the problem, MATLAB software was used. Table 4 contains the values of the column matrix $\mathrm{Y}$ and matrix $\mathrm{X}^{\mathrm{T}}$.

Table 4. Sample of values used for linear multiple regression analysis

\begin{tabular}{ccc}
\hline Matrix $Y=\Delta \eta$ & \multicolumn{2}{c}{ Matrix $\mathrm{X}^{\mathrm{T}}$} \\
\hline 0.1169 & 3 & 110 \\
0.1029 & 2 & 132 \\
0.1547 & 1 & 180 \\
\hline
\end{tabular}

After executing the calculation code using MATLAB software, the following results were obtained:

$$
\alpha_{2}=0.0019 ; \quad \alpha_{1}=0.00102 ; \alpha_{0}=-0.0403
$$

Therefore, the evolution in the efficiency reduction as a function of rated power $\left(\mathrm{P}_{\mathrm{u}}\right)$ and the number of rewinding $\left(\mathrm{N}_{\mathrm{R}}\right)$ is as follows:

$$
\Delta \eta=0.0019 * N_{R}+0.00102 * P_{u}-0.0403
$$

The model is well chosen because the error is very small, and the criterion of validation is well checked:

$$
\mathrm{C}_{\mathrm{r}}=\frac{\|\mathrm{e}\|^{2}}{\|\mathrm{y}\|^{2}}=2.9 \%
$$

Even if the error was higher than $3 \%$, our method remains relevant and applicable as long as the error is less than $5 \%$ because it is easier. Moreover, the model is more accurate with a large number of motors. These calculations will be performed one time, and the user has the ability to update the numerical model if other samples need to be inserted into the calculation. 


\subsection{Determination of the critical efficiency}

The objective of this section is to define an optimization criterion that will help the energy manager of an industrial plant make the right decision to rewind or acquire a new motor based on the critical efficiency. We will determine the critical efficiency that the motor must have so that the motor cost and the rewinding cost do not exceed $70 \%$ of the cost of a new motor.

- The energetic overconsumption $(\Delta \mathrm{C})$ in $\mathrm{kW}$ is:

$$
\Delta \mathrm{C}=\mathrm{P}_{\mathrm{u}} \times\left(\frac{1}{\eta_{\mathrm{a}}}-\frac{1}{\eta_{\mathrm{n}}}\right)
$$

- The overconsumption cost $(\mathrm{Ce})$ is:

$$
\mathrm{C}_{\mathrm{e}}=\Delta \mathrm{C} \times \mathrm{K} \times €
$$

where $\epsilon$ is the cost per KWh and $\mathrm{K}$ is the coefficient of the use of the motor.

- Cost of rewinding an electric motor:

The cost of rewinding $\left(\mathrm{C}_{\text {rew }}\right)$ electric motors consists of two main elements: the cost of the raw material $\left(\mathrm{C}_{\mathrm{rm}}\right)$ that varies from one motor to another according to the technology and the motor power. There is also the cost of worker $\left(\mathrm{C}_{\mathrm{mp}}\right)$, which is calculated as follows:

$$
\mathrm{C}_{\mathrm{mp}}=\mathrm{T}_{\mathrm{b}} \times \mathrm{N}_{\mathrm{e}} \times \mathrm{T}_{\mathrm{h}}
$$

where $T_{b}$ is the time for rewinding the motor, $N_{e}$ is the number of operators and $T_{h}$ is the hourly rate cost. The cost of rewinding $\left(\mathrm{C}_{\text {rew }}\right)$ is given by:

$$
\mathrm{C}_{\mathrm{rew}}=\mathrm{C}_{\mathrm{mp}}+\mathrm{C}_{\mathrm{rm}}
$$

- Motors rewound several times:

The critical efficiency is the efficiency, which will generate an energy over-cost plus the rewinding cost carried out during $\mathrm{T}_{\mathrm{m}}$, which is equal to the $70 \%$ of the cost of acquiring $\left(\mathrm{C}_{\mathrm{acq}}\right)$ a new motor, hence the following equations:

$$
\mathrm{F} \times \mathrm{C}_{\mathrm{rew}}+\mathrm{C}_{\mathrm{e}}=0.7 \times \mathrm{C}_{\mathrm{acq}}
$$

where $F$ represents the rewind frequency performed during $T_{m}$.

$$
0.7 \times \mathrm{C}_{\text {acq }}-\mathrm{F} \times \mathrm{C}_{\text {rew }}=\mathrm{P}_{\mathrm{u}} \times\left(\frac{1}{\eta_{\mathrm{c}}}-\frac{1}{\eta_{\mathrm{n}}}\right) \times \mathrm{T}_{\mathrm{m}} \times \mathrm{K} \times €
$$

Thus, the critical efficiency is:

$$
\eta_{\mathrm{c}}=\frac{1}{\frac{0.7 \times \mathrm{C}_{\mathrm{acq}}-\mathrm{F} \times \mathrm{C}_{\mathrm{rew}}}{\mathrm{Pu}_{\mathrm{u}} \times \mathrm{T}_{\mathrm{m}} \times \mathrm{K} \times €}+\frac{1}{\eta_{\mathrm{n}}}}
$$

\section{EXPERIMENTAL RESULTS}

Three induction motors where use in this experimental, shown in Table 5, are not part of the group of motors for which the numerical model is obtained. To validate, the proposed method, shown in Figure 3, will be applied to test these three induction motors with different ratings: $110 \mathrm{~kW}, 160 \mathrm{~kW}$, and $300 \mathrm{~kW}$. The efficiency reductions obtained by the application of the proposed algorithm are compared to those obtained from the separate losses method used as a reference, the modified current method and the simple current method [24, 25]. The results are presented in Figure 4.

Table 5. Nameplate information of the motors

\begin{tabular}{ccccccccc}
\hline No. & $\mathrm{U}(\mathrm{V})$ & $\mathrm{F}(\mathrm{Hz})$ & $\mathrm{P}_{\mathrm{u}}(\mathrm{kW})$ & $\mathrm{N}_{\mathrm{R}}$ & $\cos \phi$ & $\mathrm{I}(\mathrm{A})$ & $\mathrm{RPM}(\mathrm{r} / \mathrm{min})$ & $\eta_{\mathrm{n}}(\%)$ \\
\hline 1 & $380 / 660$ & 50 & 110 & 1 & 0.85 & 117.5 & 1480 & 93 \\
2 & $380 / 660$ & 50 & 160 & 1 & 0.88 & 168 & 1485 & 94 \\
3 & $380 / 660$ & 50 & 300 & 2 & 0.89 & 307 & 1400 & 95 \\
\hline
\end{tabular}




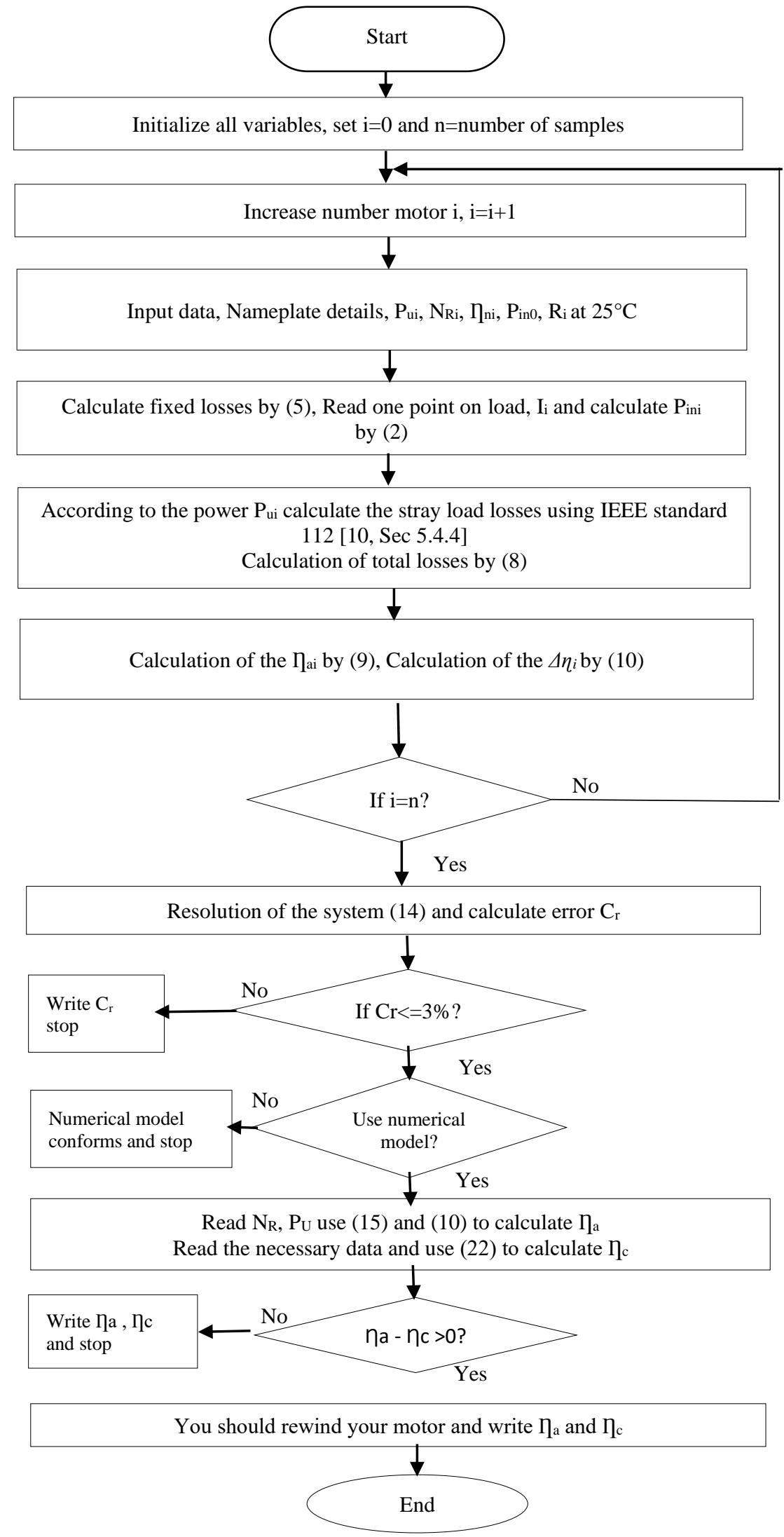

Figure 3. Flowchart of the proposed technique 


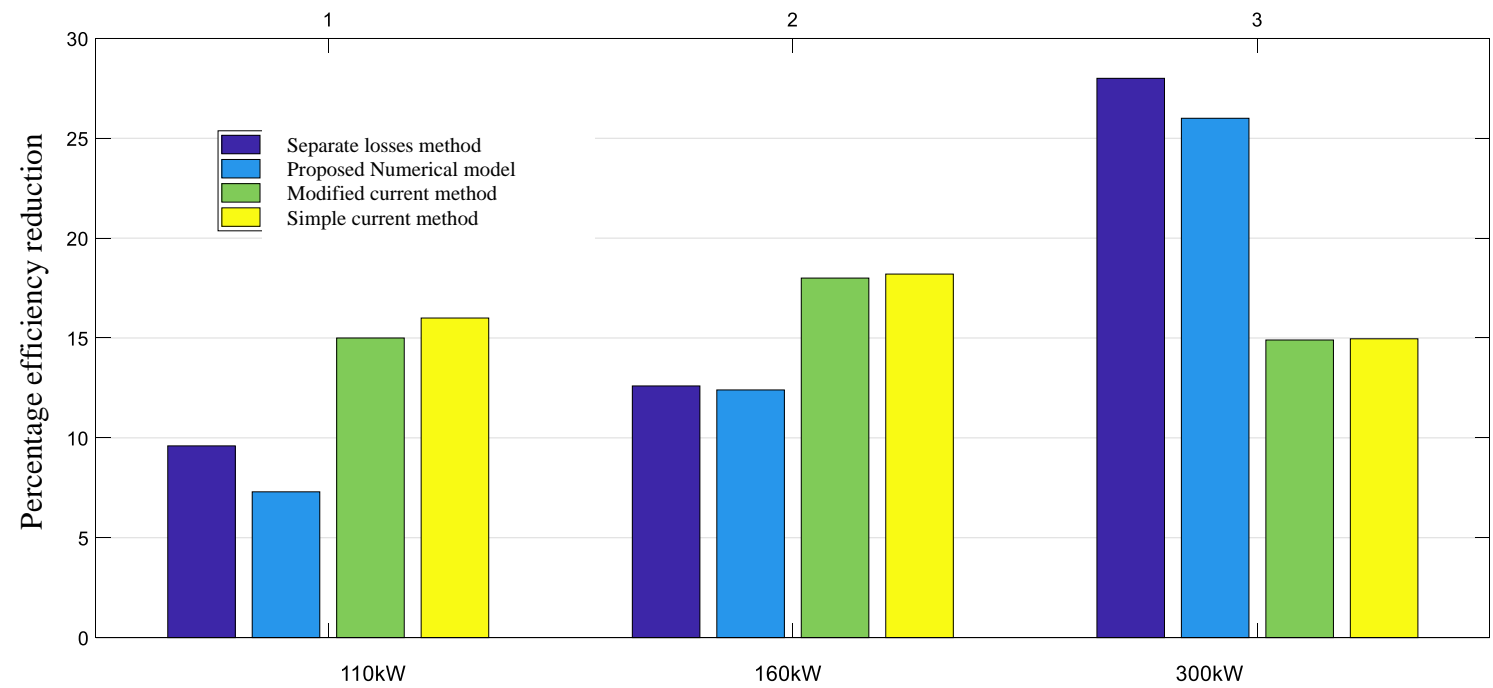

Figure 4. Comparison of experimental results of each motor with the numerical results

\section{DISCUSSION}

The results provided by separate losses method and numerical model are similar. Predicting the efficiency of the rewound motor by this approach is more accurate than that of the modified current and simple current methods. This numerical model allows us to assess the overconsumption to decide between rewinding or buying a new electrical motor. By analyzing Figure 2, the reduction in efficiency is approximately linear and is aggravated with the power of the motors. Therefore, for powerful motors, a very high efficiency reduction is demonstrated compared to the motors with small powers. Normally, the rewinding of large horsepower motors is economically viable [26]. However, in some countries, repairing electrical motors causes a serious decrease in the efficiency compared to what occurs in other countries. This shows the advantage and the relevance of our approach to estimate efficiency. Hence, there is a need to develop an easy and valid technique that considers the specificity of each country and the level of expertise in terms of rewinding practices and procedures.

The reduction in efficiency varies remarkably according to the power of the motor and the number of rewindings. Therefore, we can use the previous equation to predict the performance of a motor from the same site before rewinding it. This model can also be used to evaluate the losses in the rewound motors for a site that demonstrates the same rewinding practices or the same repairs. Then, application of this model is not restricted to the group of motors for which numerical model was derived. This information will be very useful for evaluating the extra energy cost that will be generated by the reduction in efficiency after each rewinding operation. Sometimes the extra energy cost exceeds the purchase price of a new motor.

Note that the coefficients of this numerical model will change if the refurbishment conditions are changed or the rewinding process is improved, which can be used to audit the repair quality of electrical machines. This is a strong indicator to audit repairers according to their expertise, knowing that the change in rewinding procedures is very long and depends to some extent on the skills of the staff involved. This method is applicable in other industrial sites, and it is only necessary to apply the algorithm mentioned in section 5 with the corresponding numerical model. The relevance of the method depends on the steps chosen, the precision of the numerical calculation, and the inaccuracies related to the operating conditions, namely, the measurement of the resistance's stator at $25^{\circ} \mathrm{C}$, the power factor under no-load conditions, the measurement instrument used and whether the copper losses in the rotor are ignored or not. The results reveal that the proposed method can evaluate the efficiency of induction motor with less than $3 \%$ error under normal load conditions.

\section{CONCLUSION}

This paper has presented a new approach for the estimation efficiency of rewound induction motors in situ. For this purpose, the measurements of the no-load test after refurbishment of more than 101 induction motors were used. The relationship between the efficiency reduction and number of rewindings on the one hand and between efficiency reduction and rated power on the other hand are combined to obtain a numerical model. The proposed method was tested by three categories of motors $(110 \mathrm{~kW}, 160 \mathrm{~kW}, 300 \mathrm{~kW})$ in situ;

Estimation efficiency of rewound induction motors in situ using a numerical model (Mohamed Kaddari) 
the results are compared with the separate losses method, modified current method and simple current method. The experimental results show that the proposed method is more accurate than the modified current method and simple current method.

The advantages of the proposed method are described as follows: the method is a simple procedure that does not require decoupling the motor from its process, is inexpensive, efficient and accurate and uses only the results of no-load tests of the refurbished motors. Note that by using this model, the overconsumption of plants that contain several rewound motors will be estimated accurately. The critical efficiency provides reliable information for the decisions to directly replace induction motors with more efficient motors. Another major contribution of this paper is that this method can be used to satisfy the lack of information recorded in the software tools for the optimization of energy to predict reduction in the efficiency after refurbishment and can be considered as the first indicator of repair quality. The algorithm is designed to be without difficulty and can be applied to any motor rewinding workshop or industrial plant.

\section{REFERENCES}

[1] A. McKane and A. Hasanbeigi, "Motor system energy efficiency supply curves: A methodology for assessing the energy efficiency potential of industrial motors systems,'” Energy Policy, vol. 39, no. 10, pp. 6595-6607, 2011.

[2] M. Kaddari, M. El Mouden, and A. Hajjaji, "Evaluation of energy savings by using high efficiency motors in Thermal Power Station," International Journal of green Energy, vol. 14, no. 10, pp. 839-844, 2017.

[3] C. T. Raj, S. P. Srivastava, and P. Agarwal, "Energy efficient control of three-phase induction motor-a review," International of Computer and Electrical Engineering, vol. 1, no. 1, pp. 61-70, April 2009.

[4] V. P. Sakthivel, R. Bhuvaneswari, and S. Subramanian, "Bacterial foraging technique based parameter estimation of induction motor from manufacturer data," Electric Power Components and Systems, vol. 38, no. 6, pp. 657-674, 2010.

[5] E. Boudissa and M. Bounekhla, "Genetic algorithm with dynamic selection based on quadratic ranking applied to induction machine parameters estimation," Electric Power Components and Systems, vol. 40, no. 10, pp. 1089-1104, 2012

[6] M. S. Aspalli, S. B. Shetagar, and S. F. Kodad, "Estimation of induction motor field efficiency for energy audit and management using genetic algorithm," 3rd International Conference on Sensing Technology, pp. 440-445, 2008.

[7] H. Nagendrappa and P. Bure, "Energy audit and management of induction motor using field test and genetic algorithm," Int J Recent Trends Eng, vol. 1, no. 3, pp. 16-20, 2009.

[8] M. Al-Badri, P. Pillay, and P. Angers, "A novel algorithm for estimating refurbished three-phase induction motors efficiency using only no-load tests," IEEE Transactions on Energy Conversion, vol. 30, no. 2, pp. 615-625, 2015.

[9] N. El Khattabi, "Identification parameters of induction motor for measuring efficiency in situ," Ph. D. Thesis, University of Quebec Three Rivers, Canada, Feb. 2009.

[10] W. Cao, "Comparison of IEEE 112 and new IEC standard 60034-2-1," in IEEE Transactions on Energy Conversion, vol. 24, no. 3, pp. 802-808, 2009.

[11] A. G. Siraki, P. Pillay, and P. Angers, "Full load efficiency estimation of refurbished induction machines from no-load testing," in IEEE Transactions on Energy Conversion, vol. 28, no. 2, pp. 317-326, 2013.

[12] M. Kaddari, M. El Mouden, A. Hajjaji, and D. Saifaoui, "Optimal maintenance of the electric motors to improve the energy efficiency," in Proc. of International Conference on Materials \& Energy (ICOME'15), pp. 1-6, 2015.

[13] R. Saidur, "A review on electrical motors energy use and energy savings," Renewable and Sustainable Energy Reviews, vol. 14, no. 3, pp. 877-898, 2010.

[14] S. Subramanian and R. Bhuvaneswari, "Evolutionary programming based determination of induction motor efficiency," Electric Power Components and Systems, vol. 34, no.5, pp. 565-576, 2006.

[15] Bin Lu, T. G. Habetler, and R. G. Harley, "A survey of efficiency-estimation methods for in-service induction motors," in IEEE Transactions on Industry Applications, vol. 42, no. 4, pp. 924-933, 2006.

[16] V. P. Sakthivel, R. Bhuvaneswari, and S. Subramanian, "Non-intrusive efficiency estimation method for energy auditing and management of in-service induction motor using bacterial foraging algorithm," IET Electric Power Applications, vol. 4, no. 8, pp. 579-590, 2010.

[17] C. A. Wengerkievicz, R. D. A. Elias, N. J. Batistela, N. Sadowski, P. Kuo-Peng, S. C. Lima, P. A. Silva Jr., and A. Y. Beltrame, "Estimation of three-phase induction motor equivalent circuit parameters from manufacturer catalog data," Journal of Microwaves, Optoelectronics and Electromagnetic Applications, vol. 16, no. 1, pp. 90-107, 2017.

[18] M. Sertsöz, M. Fidan, and M. Kurban, "Efficiency estimation of induction motors at different sizes with artificial neural networks and linear estimation using catalog values," Anadolu Üniversitesi Bilim Ve Teknoloji Dergisi A-Uygulamalı Bilimler ve Mühendislik, vol. 19, no. 2, pp. 293-302. 2018.

[19] B. Koprivica, M. Božić, M. Rosić, and M. Bjekić, "Application of standard and modified eh-star test method for induction motor stray load losses and efficiency measurement," Serbian Journal of Electrical Engineering, vol. 9, no. 3, pp. 377-391, 2012.

[20] O. Bottauscio, M. Chiampi, A. Manzin, and Zucca, "Prediction of losses in induction machines: a challenge for the modelling approaches," The European Physical Journal Applied Physics, vol. 30, no. 1, pp.7-16, 2005.

[21] H. R. Khoei and E. F. Hahraki, "Fuzzy logic based direct power control of induction motor drive," Bulletin of Electrical Engineering and Informatics, vol. 5, no. 3, pp. 296-306, 2016. 
[22] J. L. Febin Daya, "Machine model based speed estimation schemes for speed encoderless induction motor drives: A survey," Bulletin of Electrical Engineering and Informatics, vol. 4, no. 1, pp. 7-17, 2015.

[23] K. Komeza and M. Dems, "Finite-element and analytical calculations of no-load core losses in energy-saving induction motors," IEEE Trans. On Indust. Electronics. vol. 59, no. 7, pp. 2934-2946, 2012.

[24] M. Kaddari, M. El Mouden, and A. Hajjaji, "Application on-site and comparison of efficiency estimation methods for induction motors," Proceedings of the 10th international conference on energy efficiency in motor driven system (EEMODS' 2017), pp. 547-561, 2017.

[25] C. P. Salomon, W. C. Sant'Ana, G. Lambert-Torres, L. E. Borges da Silva, E. L Bonaldi, and L. E. D. L. De Oliveira, "Comparison among methods for induction motor low-intrusive efficiency evaluation including a new AGT approach with a modified stator resistance," Energies, vol. 11, no. 4, pp. 1-21, 2018.

[26] M. Hasanuzzaman, N. A. Rahim, and R. Saidur, "Analysis of energy savings for rewinding and replacement of industrial motor," 2010 IEEE International Conference on Power and Energy, pp. 212-217, 2010.

\section{BIOGRAPHIES OF AUTHORS}
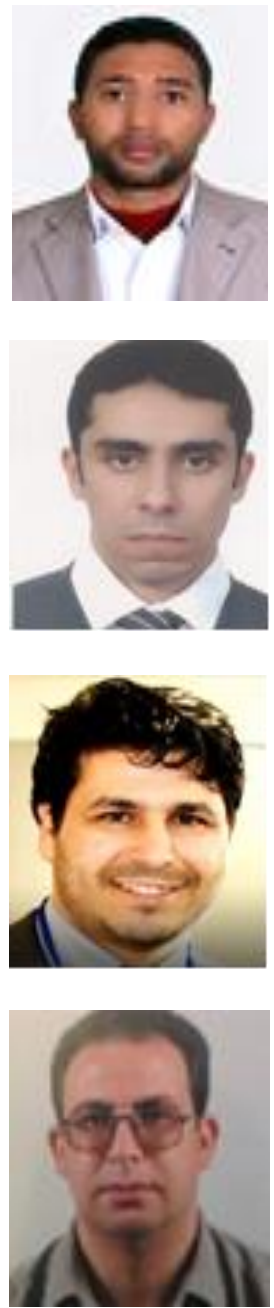

Mohamed Kaddari was born in Morocco, in 1982. He received the specialized Master degree in Renewable Energy and Energetic Systems in 2013, from Faculty of Sciences, HASSAN II University of Casablanca. Mr. Kaddari is currently pursuing the Ph.D. degree with the Laboratory of Sciences of the engineer for energy (LabSIPE), National School of Applied Sciences, Chouaib Doukkali University. His research interests include savings electrical energy in the electric-machine, efficiency estimation in situ and diagnosis of induction motor.

Mahmoud El Mouden was born in Morocco, in 1978. He received the D.E.S.A's degree and $\mathrm{PhD}$ degree in Physics of Plasmas in 2002 and 2006, respectively, from Faculty of Sciences, HASSAN II University of Casablanca. He is currently co-head of Science Department of Industrial Technology (STIN) at National School of Applied Sciences (ENSAJ) and member of the Laboratory of Sciences of the engineer for energy (LabSIPE), El Jadida, Morocco.

Abdelowahed Hajjaji was born in Morocco. He received his master's degree in Materials Sciences from National Institute for Applied Sciences, Lyon France, in 2004 and his Ph.D. degree in Materials Behaviors, Vibration Control and Energy Harvesting in 2007. He obtained his Habilitation from National School of Applied Sciences (ENSAJ), El Jadida, Morocco in 2014. He is currently Head of Laboratory of Engineering Sciences for Energy at Chouaib DOUKKALI University. His current research activities include piezoelectric systems, energy harvesting, vibration control, and noise reduction.

Abdellah Semlali was born in Morocco. He is currently working as Professor in the Department of Physic; He is having 33 years of teaching experience from Chouaib Doukkali University. $\mathrm{He}$ has published several International Journal papers in the Molecule-solid interactions and Physical adsorption field. Mr. Semlali is the head of the research team "Physics of Surfaces and Interfaces" at Laboratory of Condensed Matter Physics (LPMC), El Jadida, Morocco. His present research interests are Electrical Machines and Power Quality. 